a preliminary to tracheotomy; secondly, as a measure in anaesthesia.

It is important at the outset to make it clear that the manœurre does not call for special skill. Magill has pointed out that provided the catheter is bent to the correct shape upon its stylet-roughly speaking, a capital C - it is merely necessary to lubricate it and push gently, the operator being guided largely by the intensity of the respiratory sounds heard at the proximal end of the catheter. Certainly I have been able to endorse this dictum upon two out of the three occasions on which $I$ have tried the manœuvre. In any case, the passage of a catheter is likely to be easier than the operation of tracheotomy; and in the event of failure the patient's chances with tracheotomy are not jeopardized.

\section{In Respiratory Gbstruction.}

I have not yet attempted intubation of the larynx via the nose in the obstruction of diphtheria; but, sueh cases for the moment apart, I would make a strong' plea for an attempt at the passage of an endotracheal catheter as a regular preliminary to the operation of tracheotomy. If it is successfully passed, what was an emergeney becomes a routine; and a step is at once taken towards the elimination of operative risks in tracheotomy. Further, if intubation has been achieved with cocaine, the way is now clear for an easy induction of general anaesthesia if this should seem preferable to the use of novocain. If it should fail, neither patient nor operator is much worse off. It is possible even that cases of temporary obstruction may arise where this form of intubation may replace tracheotony, as it sometimes does in diphtheria ferer practice. This suggestion was made long ago by Dr. Magill, in a rerbal communication.

\section{For Anaesthesia in Throat Operations.}

The real bugbear of general anaesthesia at the present time is no longer the risk to life, but, to doctor and patient alike, is rather the risk of post-operative romiting. While many anaesthetists are now accustomed to give gas and oxrgen for tonsillertomy provided the endotracheal catheter can be introduced after a preliminary induetion with etlier, the introduction of a catheter without the help: of an ether induction or of the deep sleep afforded by paraldehyde - that is to say, under the influence of gas only-must be regarded as a great achievement. It is seldom, therefore, that the prospect of gas and oxygen anaesthesia throughout the operation enables us to promise the patient complete freedom from post-operative vomiting. If, however, the catheter could be introduced as a routine measure under local anarsthesia, throat operations could easily be performed under gas and oxygen anaesthesia only-that is to say, throat operations would be free from any risk of post-operative remiting.

\section{Before Emergency Trach cotomy.}

The case above described is one of two in which I have performed endotracheal intubation via the nose undes local anaesthesia without the help of vision as a preliminary to tracheotomy; but upon three other occasioas. I have carried out intubation of the trachea as a preliminary to: emergency tracheotomy, once with gas and twice with ether.

The first case was that of a woman whose traehea was obstructed by a large carcinema of the thyroid gland. The operation of tracheotomy proved difficult even after the intuliation, and would certainly have been a terrifying ordeal without it. In the second case intubation via the nose was done as a preliminary to tracheotomy in a case of tracheal olstruction of unexplained origin-pessibly a retrosternal goitre -occuring during an operation upon the tonsils. It proved unnecessary to proceed to tracheotemy, as normal respiration was restored on the patient's recovery from the anaesthetie, when the tube was: removed. The third rase was that of a child, aged 7 , in whom the olwstrution was caused by sub. glottic oedema following bronchoseofy for foreign body. A little gas in this weak child suffieed to permit of intubation.

\section{Conchesion.}

The purpose of this article is chiefly to put forward a proposal that tracheotomy should be preceded as a routine by an attempt at intubation of the trachea, with a view to rendering the operation easier and safer of performance; and that the nasal route should be chosen rather than the buccal, whether local or general anaesthesia be employed. To this end it is urged that the tracheotomy set which should have a place in every operating theatre should comprise a catheter suitably eurved upon a stylet, with a spray duly charged with cocaine; and that students should be shown the manœuvre of nasal intubation-for example, during their period of anaesthetic instruction. The acquisition of familiarity with this simple procedure should render a house-physician's first tracheotomy a less alarming affair than it sometimes proves.

$$
\begin{gathered}
\text { REFERENCEs. } \\
1 \text { proc. Roy. Soc. Med., February, 1921, p. 17. } 2 \text { Ibid., Deccmiber, } \\
\text { 1928, p. 83. }
\end{gathered}
$$

\section{THE ETIOLOGY OF HIGH BLOOD PRESSURE.}

$\mathrm{BY}$

R. G. W.ALLER, M.R.C.S., I..R.C.P.,

JLNIOR ASSISTANT PATHOLOGIST TO WESTMINSTER HOSPITAL.

(From the John Burford Carlill Laboraturies, Westminster IIospital.)

A stror of the published work on high blood pressure shows that many views have been put forward to account for its incidence. The following is a summary of the varions factors which have heen held to be implicated in its etiologr.

1. Hereditary influence.

2. Infection (past or present).

(a) Generalized systemic infections.

(b) Focal infections with dissemination of organisms.

(c) Focal infections with dissemination of toxins.

3. Intoxications (non-infectious) :

(a) Exogenous: (i) lead, arsenic; (ii) alcohol (doulstful); (iii) dict-excess of meat, general excess, condiments, constipation.

(b) Endogenous.

4. Metabolic:

(a) Pregnancy.

(b) Fatigue.

(c) Endocine disturbince.

It is known that high blood pressure is in most cases accompanied by arterial or renal degeneration; it is also recognized that pathological degenerations are preceded by, and are therefore presumably the result of, some form of toxaemia. Hence it is not unreasonable to suppose that high blood pressure is the result of the action of some toxic body or bodies. Since it one of the chief functions of the liver to destroy toxic substances, it was eonsidered that it might prove possible to show that the hepatic detoxicating functions are impaired in cases of hypertension.

On the assumption that high hlood pressure is the result of a toxaemia, a considerable amount of work has been done in the past to establish the existence of a causative toxin, without its having proved possible to implicate. definitely any one class of toxin, and much less any specific toxic body. For the purposes of this present investigation the most promising field in which to search for a causative toxin seemed to be among the products of protein disintegration, since it is toxic bodies of this nature-for example, indican-which are chiefly destroyed by the liver. The investigation therefore resolved itself into an examination of the products of protem metabolism, and of the ability of the liver to deal with such preducts.

To this end full blood analyses, with reference to nitrogen partition, were made; the hepatic detexicating funetions 
were judged in terms of the capability of the liver to destroy indican, and to combine drugs of the nature of salicylic acid with glycuronic acid, excreting them as the paired glycuronates. The determination of nitrogen partition involved the estimation in the blood of urea, nonprotein nitrogen, amino-acids, and purins. It was anticipated that the presence of any non-protein nitrogenous toxin would show itself either as a relative increase of non-protein nitrogen over urea, or, if it should be of the nature of a specific amino-acid, it would naturally be found in this fraction of the analysis.

In order to determine whether or not the liver was dealing with the metabolism of nitrogenous bodies in an efficient manner, estimations of the relative amount of ammonia nitrogen and urea nitrogen in the urine were carried out. It is assumed that a normally functioning liver converts all but about 3 per cent. of ammonia, produced as a result of deaminization, into urea; so that a normal ammonia nitrogen to urea nitrogen ratio is in the neighbourhood of 1 to 60 , and should not in any case exceed 1 to 35 .

Twenty-five cases of hypertension with systolic blood pressures varying between 185 and 300 millimetres of mercury, and twenty control cases in which hypertension was not present, were investigated. The mininum, maximum, and average results in both series of cases are shown in the following tables. Full experimental details showing the actual figures obtained in each individual case are available, and will be furnished on application to the author.

Cases of Hypertension.

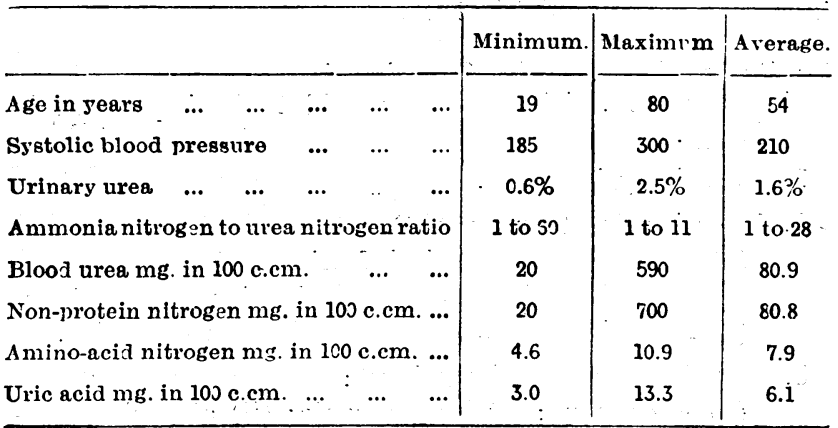

"Normal" Control Cases.

\begin{tabular}{|c|c|c|c|c|c|}
\hline & \multirow{2}{*}{$\frac{\text { Minimum }}{9}$} & \multirow{2}{*}{$\frac{\text { Maximum }}{65}$} & \multirow{2}{*}{$\frac{\text { Average }}{38}$} \\
\hline Age in years & ... & $\ldots$ & & & \\
\hline Systolic blood pressiurs & $\ldots$ & $\ldots$ & 88 & 142 & 115 \\
\hline Urinary urea $\quad \ldots \quad \ldots$ & .. & $\ldots$ & $1.6 \%$ & $2.5 \%$ & $2.0 \%$ \\
\hline \multicolumn{3}{|c|}{ Ammonia nitrogen to urea nitrogen ratio } & 1 to 88 & 1 to 32 & 1 to 61 \\
\hline \multicolumn{3}{|c|}{ Blood urea mg. in $100 \mathrm{c.cm} . \quad \ldots \quad \ldots$} & 26 & 45 & 34 \\
\hline \multicolumn{3}{|c|}{ Non-protein nitrogen mg. in 10 ) c.cm. ... } & $\therefore 6$ & 44 & 34 \\
\hline \multicolumn{3}{|c|}{ Amino-acid nitrogen $\mathrm{mg}$ in $100 \mathrm{c} \mathrm{cm} . \ldots$} & 4.8 & 6.9 & 5.7 \\
\hline \multicolumn{3}{|c|}{ Uric acid $\mathrm{mg}$. in $10 \mathrm{~J}$ c.cm. $\ldots \quad \ldots \quad \ldots$} & 0.9 & 3.0 & 2.2 \\
\hline
\end{tabular}

Urea in the urine was estimated by the alkaline sodium hypobromite method, and the ammonia nitrogen content by titration with formalin and standard alkali.

In 68 per cent. of cases of high blood pressure the urinary urea was less than 2 per cent.; in all cases the amount of ammonia was high, so that the ratio of ammonia nitrogen to urea nitrogen was in all but four instances (16 per cent.) increased to approximately 1 to 20 . Since a condition of acidosis was eliminated by simultaneous determination of the alkali reserve of the patient the conclusion must be drawn that the absolute and relative increase in urinary ammonia is due to an hepatic lesion. All the control eases gave normal ammonia nitrogen to urea nitrogen values.

The detoxicating functions of the liver were tested by two independent means: (1) an estimation of urinary indican by oxidation to indigo with Obermayer's reagent, and (2) the detection of glycuronic acid in the urine by Tollen's naphthoresorcinol test after the ingestion of 10 grains of acetyl-salicylic acid. The results did not show that there was any inipairment of detoxicating function of the liver as indicated by the glycuronic acid test, since only three of the series gave a definitely negative result. Of these three, one was a case of diabetes mellitus with high blood pressure in an elderly patient, such. diabetes being frequently of hepatic as well as of pancreatic origin; hence it is not surprising that other liver functions were also found to be inefficient. In this case also there was evidence of inefficient pretein metabolism, as indicated by a high ammonia nitrogen to urea nitrogen ratio ( 1 to 19). Two other patients were aged 70 and 80 years respectively; at this age it is not unreasonable to suppose that hepatic functions are deficient, apart from any specific disease.

An excess of indican was found in 72 per cent. of the cases; it is evident that this must be due either to an excessive production or to a loss of hepatic oxidative power. Although indican in itself is not toxic, its presence in excess in these cases is of significance because of its association with the high amino-acid content observed in 17 out of 25 of these cases. There was no history of constipation or of intestinal disturbance in any of these patients, so that a long-standing intestinal toxaemia to account for an excess of indican is improbable.

Blood urea was determined by means of alkaline sodium hypobromite controlled by the soya bean method; in all cases the results did not differ by more than 2 per cent. Non-protein nitrogen was estimated by the micro-Kjeldahl method, and blood amino-acids ${ }^{2}$ and blood purins ${ }^{3}$ by the method of Folin. Blood urea values were in all cases increased beyond the normal of 25 to $40 \mathrm{mg}$. per $100 \mathrm{c.cm}$. results as high as $590 \mathrm{mg}$. pèr $100 \mathrm{cccm}$. being obtained. The figures representing non-protein nitrogen, although raised, were not increased to such an extent as was the blood urea, so that figures less than the blood urea values were frequently obtained.

An increased amount of amino-acid nitrogen was found in 68 per cent. of this series of cases, figures varying from 5 to $10.9 \mathrm{mg}$. per $100 \mathrm{c.cm}$., instead of the normal 4 to $6 \mathrm{mg}$. per 100 c.cm., being obtained; this is in the main associated with a normal or relatively low blood urea content. It was also noticeable in those cases in which the blood urea was raised that the amino-acid nitrogen was more or less normal. This may be due to the fact that when there is serious impairment of renal function, as shown by an abnormally high blood urea, there is at the same time a certain amount of inorganic salt retention, with consequent hydraemia and dilution of blood constituents. The relatively low values of amino-acid found in these cases, in conjunction with a high blood urea, are therefore probably more apparent than real. It is of interest to note that these findings are at variance with those of Greene, Sandiford, and Ross, ${ }^{4}$ who observed no increase in blood amino-acids in a series of 20 cases of hypertension and arterio-sclerosis in which the blood urea was normal.

One is left, therefore, to conclude that the increase in the amino-acid content of the blood is due either to an inability of the liver to deaminize these compounds, or to an impairment of renal function interfering with their excretion. Since in most cases of both acute and chronic renal disease there is no marked retention of amino-acids, it is probable that the increase observed in this series of cases (in which renal involvement is not particularly evident) is due to some form of liver degeneration. The suggestion that liver degeneration is responsible for the increase in amino-acids is supported by the fact that these bodies are very markedly increased in acute yellow atrophy of the liver. ${ }^{4}$

That an increase of amino-acids does in point of fact cause a rise in blood pressure is shown by the experiments of Major Stevenson, ${ }^{5}$ who demonstrated that injections of guanidine and methylguanidine (both of them amino-acids) produced a marked increase in blood pressure. In this connexion also it is again of interest to note that Woolley and Newburgh" have shown that the long-continued injection of the amino-acid indol causes hypertrophy of the 
suprarenal medulla. Since it is in this tissue that the produrction of adrenaline takes place, it seems not unlikely that hyperadrenalism may be an associated factor in hypertension, and that its existence may be reflected in the high anino-acid content. 'This relationship is to be the subject of further investigation.

Associated with the increase in amino-acids in this present series of cases, it was noted that there is also a very marked increase in the blood purins ${ }^{7}$ (cstimated as uric acid); values varying between 4.0 and $13.3 \mathrm{mg}$. per 100 c.cm., instead of the normal 1.0 to $3.0 \mathrm{mg}$. per 100 c.c.m., were obtained. The significance of this finding is not elear, beeause it is known that uric acid of itself has no influence upon blood pressure; in gout, for example, there is an increase in blood uric acid without any accompanying inerease in blood pressure.

There is also to be noted the question of the markedly raised cholesterol content of the blood in hypertension recorted by varions observers. ${ }^{8}$ That cholesterol in itself is not responsible for this pathological condition is at once obvious when the large number of patients suffering from hypercholesterolaemia, following upon biliary obstruction, pernicious anaemia, diabetes mellitus, and pregnancy, without concomitant affection of the blood pressure, is taken into consideration. However, it is said that repeated injections of cholesterol into experimental rabbits results in arterio-sclerosis. ${ }^{9}$

The source of the increased cholesterol content of the blood is probably referable to an alteration in the cholesterol metabolism taking place in the liver, and it may be said, therefore, that the hypercholesterolaemia is primarily a liver condition. The cholesterol normally excreted by the liver, together with the bile pigments, bile salts, and other biliary constituents, is derived partially exogenously and partially endogenously; that is to say, partly from sterols ingested as food, and partly from the fatty constituents derived from the breakdown of red blood corpuscles, which is said to occur in the Kupffer cells of the lirer. The sterols are converted by the liver, partly into (hrolesterol, and partly into bile salts, ${ }^{10}$ and it may well he that owing to the action of some toxic body upon the liver cells the normal course of metabolism is modified in farour of a production of cholesterol at the expense of bile salts. Such an altered course of metabolism is known to occur, and, indeed, is held to be a factor in the causation of gall-stones." Hypercholesterolinemia is therefore probably an associated factor in, rather than a cause of, high hood pressure; but this also is to be the subject of further investivation.

That some toxic factor is concerned is strongly suggested by the work of Gheorghian, ${ }^{12}$ who found that the injection of blood from patients with high blood pressure caused a rise in blood pressure in experimental animals. It seems probable that the toxic factor is a normal product of metabolism, since it has been observed by $\theta^{\prime} \mathrm{Connor}^{13}$ that a high blood pressure resultant upon urinary obstruction in cases of enlarged prostate vields to suprapubic drainage. Retention of this specific toxic body in renal dimeate, therefore, satisfactorily explains hyperpiesis in this conclition. It is to be inferred that the toxin is present only in small amount from the fact that there is no very marked difference between the blood urea and blood non-protein nitrogen figures; indeed, the non-protein nitrogen values, as already pointed out, are remarkably low. The series of blood urea determinations in cases other than nephritis suggested that there is some slight imprirment of renal function, but not enough in itself to lead to such a degree of retention of this toxic factor as to cause an increase in blood prensure such as may reasonably be supposed to oecnr with gross damage to the kidney.

This toxic body may conceivalibly be present in excess ar a result of overproduction. This possibility is suggested by the work of Nuzum, Seegal, Garland, and Osborne, ${ }^{1.4}$ who showed that the blood pressure of a rabbit ean be rained and nodular sclerosis produced by feeding on a high protein diet for two years.

The conclusion to be drawn tentatively, therefore, from this present investigation is that hypertension is due to the presence in excess of a specific amino-acid. This excrss may be due to retention resulting from renal disease, to overproduction, or more probably to some impairment of hepatic function whereby this body is not efficiently destroyed.

Finally, I wish to record my thanks to the trustces of the John Burford Carlill Endowment for a grant which las cnabled me to carry out this work; to Dr. J. A. Braxton Hicks, direetor of the John Burford Carlill Laboratories; and to Dr. F. D. M. Hocking, assistant pathologist to Westminsier Hospital for their helpful advice; to Sir James Purres-Stewart Br, de Soura and Dr. Hildred Carlill, for permision to muke ure of cass in the wards at Westminster Hospital.

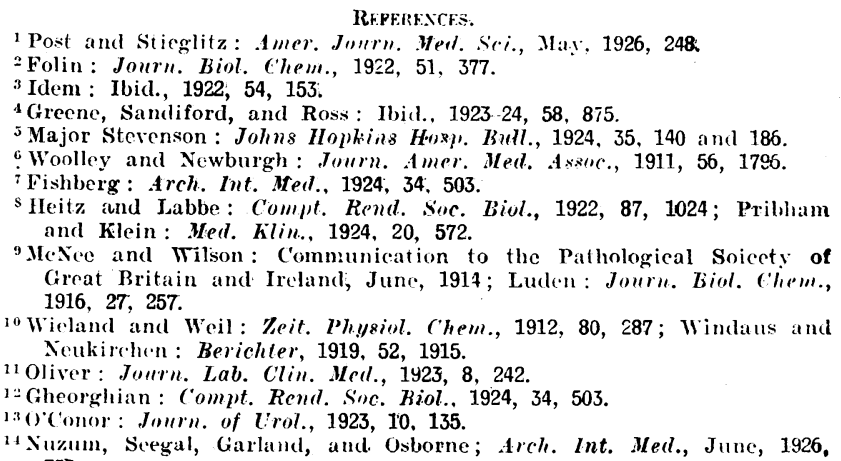

\section{PREVENTEON OF TUBERCUEOSES BY MEANS. OF TUBERCULIN.}

BY

ROBERT CARSWELL, M.A., M.B., Сн.В.

Thene is general agreement that the subcutaneous tuberculin test is a reliable test of tuberculous infection. Can anyone afford to ignore the warning furnished by such an indication, with knowledge of all the numerous minor manifestations and risks of latent tuberculosis, and of such incidents as the occurrence of tuberculous meningitis, for example, in apparently healthy children? Will any thoughtful and informed individual to-day rest completely satisfied with anything short of guaranteed absence of infection in this disease? Were infection not merely frequent and inevitable, as it appear's to be, but irremediable, as seems to be generally assumed, less might be said; and it is probable that a feeling of inevitability is the explanation of the calmness with which wholesale tuberculous infection is regarded, or disregarded, both by the medical profession and by the community at large. "We have all got it," tliey say, quite pleasantly. But such was not Koch's view, and such is not the view of those who have proved for themselves, or who accept the truth of his assertions, that his specific method of diagnosis is almost uniformly reliable, and that, in addition, incipient tuberculosis can be cured with certainty. Even if his specific methods of treatment be regarded as merely ancillary to the ordinary hygienic methods of cure, the contention that nothing short of complete eradication is a satisfactory standard would still hold force. But some of us regard specific immunization not as ancillary merely, but as a prime factor in curative and preventive treatment, though experience is required to settle the important question of exactly how far we can depend upon its help alone.

The above general argument was more or less embodied in a short paper, with three illustrative cases, published by me in the Journal four years ago (October 16th, 1926, p. 682), but since then it has become more clearly envisaged, and the following example was entered upon largely from the theoretical point of view, that in the matter of tuberculosis nothing will be completely satisfactory in the medical history of children but definite, asceitained freedom from infection, indicated by a negative tuberculin test, as is the common practice in veterinary work.

The two girls, $A$ and $B$, who an the suljects of the following report, were, at the time this record opens, 13 and $14 !$ years 